\title{
Blood pressure pattern following a combined exercise session in hypertensive older women
}

\section{Abstract}

Objective: The aim of the present study was to verify the behavior of hemodynamic variables in hypertensive older women following a combined exercise session and to identify the intensity of effort achieved in this session. Method: The study included 14 hypertensive older women (72.0 \pm 6.7 years old) who regularly practiced physical activities. The participants underwent a one-hour combined exercise session performed in a group, with intensity of effort monitored by accelerometry (Actigraph, model GT3X+). The hemodynamic parameters (systolic blood pressure, diastolic blood pressure, heart rate, stroke volume, cardiac output and peripheral vascular resistance) were individually measured by finger photoplethysmography (Finometer) before and after (60 min) the exercise session. Results: The sessions consisted predominantly of low-light intensity activities (60\%) and $20 \%$ of class time was spent on sedentary behavior. None of the evaluated variables exhibited changes when the pre and post-exercise values were compared $(p>0.05)$. Systolic blood pressure behavior correlated positively with time spent in sedentary behavior $(\mathrm{r}=0.541$; $p=0.045)$. Conclusion: The combined exercise sessions, as conducted, did not generate post-exercise hypotension. In addition, the time spent in typically sedentary activities during the classes positively correlated with changes in blood pressure, suggesting that combined exercise programs, applied in the form of collective aerobic exercises, should be composed of higher intensity activities.
Keywords: Post-Exercise Hypotension. Accelerometry. Aging. Combined Exercise.

\footnotetext{
Universidade Federal de Santa Catarina, Departamento de Educação Física, Centro de Desportos. Florianópolis, SC, Brasil.

2 Universidade Federal de Santa Catarina, Departamento de Educação Física, Centro de Desportos, Programa de Pós-Graduação em Educação Física. Florianópolis, SC, Brasil.
}

The authors declare there are no conflicts of interest in relation to the present study.

No funding was received in relation to the present study.

Matheus Pamplona Fachinil ${ }^{1 D}$ Guilherme Tadeu de Barcelos ${ }^{2}$ ID Juliana Cavestré Conegliann ${ }^{2}$ (D) Paulo Ricardo de Oliveira Medeiros ${ }^{2}$ ID Aline Mendes Gerage ${ }^{2}$ (D) 


\section{INTRODUCTION}

Systemic arterial hypertension (SAH), characterized by systolic blood pressure (SBP) values greater than or equal to $140 \mathrm{mmHg}$ and/or diastolic blood pressure (DBP) greater than or equal to $90 \mathrm{mmHh}^{1}$, is directly associated with age, with prevalences of $64 \%$ for men and $63 \%$ for women aged between 65 and 74 years ${ }^{2}$. The regular practice of physical exercise, primarily aerobic, but also that which focuses on muscle strength, is considered an essential non-drug therapy in the prevention and treatment of $\mathrm{SAH}$, as it promotes a chronic reduction in blood pressure (BP) in the older population ${ }^{1-3}$.

Furthermore, a single exercise session is capable of promoting a post-exercise reduction in $\mathrm{BP}$, when compared with pre-exercise levels or to a control session, resulting in a phenomenon known as postexercise hypotension (PEH) ${ }^{4,5}$. PEH can last for up to 24 hours, which is relevant not only because it means the cardiovascular system is exposed to elevated BP for a shorter period, but also because there are indications that individuals who are responsive to the acute effects of training tend to be responsive to chronic effects ${ }^{6-8}$.

Different factors can interfere with the occurrence and magnitude of $\mathrm{PEH}$, such as exercise intensity ${ }^{9}$, but the minimum intensity for obtaining the best regulation of BP has not yet been established. In addition, it is noteworthy that most studies investigating the PEH phenomenon have been restricted to evaluating dynamic and isometric aerobic or resistance exercises considered in isolation. However, the combined practice of different exercise modalities in the same session has rarely been investigated, especially in exercise sessions in the form of dynamic group classes, which are often practiced by older adults.

In this sense, it is noteworthy that, although programs involving dynamic group gym classes are strongly encouraged for the older population, as they promote health benefits in general ${ }^{10}$, it has still not been fully established whether the intensity achieved in training sessions, through collective classes, is suitable for achieving the expected results. A study by Borges et al. ${ }^{11}$ demonstrated, for example, that collective aerobic sessions for older adults applied in basic health units in Florianópolis (Santa Catarina) were mostly composed of activities of light or sedentary intensity, but few studies have analyzed the intensity of this type of exercise session in an objective manner through accelerometry. It is also unknown whether the intensities achieved in these exercise sessions are capable of promoting a post-exercise reduction in BP, which would possibly be associated with the occurrence of a chronic decline in BP.

Therefore, it is important to investigate whether exercise sessions, in the form of collective aerobics classes, carried out in public projects aimed at promoting physical activity, are capable of causing $\mathrm{PEH}$ in the older population, as this type of class is one of the main forms of physical activity among this population. Thus, the present study aimed to analyze the behavior of the SBP, DBP, cardiac output (CO) and peripheral vascular resistance (PVR) variables after a session of combined physical exercise (aerobic + strength), in the form of a collective class, of hypertensive older women. In addition, we sought to investigate the correlation between post-exercise $\mathrm{BP}$ responses and the effort intensities achieved by the hypertensive older adults during these sessions. Finally, the correlation between post-exercise BP responses and the behavior of the CO and PVR variables was tested only among those older women who exhibited PEH.

\section{METHOD}

The present study was carried out between August and November 2018, using a quasi-experimental design, as there was no control group and/or session. No previous sample calculation was performed, so the study sample was recruited on a voluntary basis and selected for convenience, consisting of 14 older women ( $\geq 60$ years), diagnosed with $\mathrm{SAH}$, participating in an extension program at the Universidade Federal de Santa Catarina (Santa Catarina Federal University) (UFSC) in the city of Florianópolis, Brazil, which offers collective aerobics classes aimed at this population, twice a week. To 
participate in the study, the older women were required to have been engaged in this program for at least six months and not have any more severe comorbidities (such as severe heart disease) or injuries that prevented exercise.

The study was approved by the local Ethics Committee (approval opinion number: 2,870,053), according to the rules of resolution 466-2012 of the National Health Council, and all participants signed an informed consent form (ICF), after being informed about the objectives and procedures of the study.
There were 14 sessions of combined exercises in the form of collective classes, with each participant being evaluated in one of these sessions, which were organized and structured in a similar way. In each assessment, at the beginning of the program, anthropometric and resting BP (pre-exercise) data were collected from the participants. Subsequently, an accelerometer was attached to each individual, above the iliac crest, before the beginning of the gym class, so that the intensity of the class was recorded. At the end of the session, the accelerometer was collected and BP was measured again over a 60 minute period (post-exercise) (Figure 1).

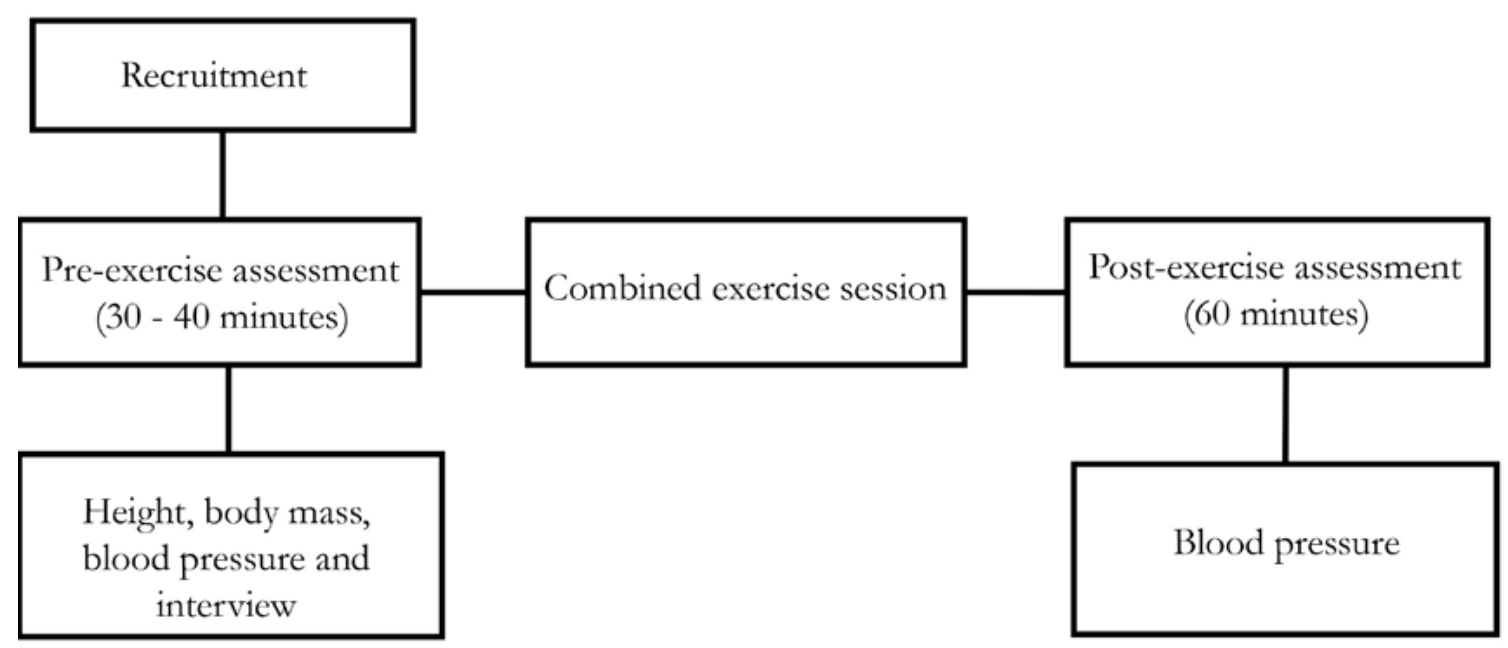

Figure 1. Experimental design of study. Florianópolis (Santa Catarina), Brazil, 2018.

For the general characterization of the sample, body mass measurements were performed using an Omron HBF-540C digital reading scale, with $0.1 \mathrm{~kg}$ accuracy, and height was taken with a stadiometer with $0.1 \mathrm{~cm}$ accuracy. From these measurements, the Body Mass Index (BMI) was calculated, with the division of body mass (in $\mathrm{kg}$ ) by square height (in meters). Information was also collected about the marital status of the participants through an interview.

The finger photoplethysmography technique, with a single Finometer device (FMS - Finapress Medical System, Netherlands), was used to analyze the hemodynamic variables, beat by beat, in a noninvasive manner, in the pre- and post-exercise phases, by two previously trained evaluators, who performed all assessments in a standardized manner and followed all procedures according to the recommendations given by the manufacturers of the instruments used. The variables evaluated were SBP and DBP, heart rate (HR), stroke volume (SV), CO and PVR.

The older adults were instructed not to drink any type of caffeinated beverage, such as green tea, coffee or soda, for at least 12 hours before the evaluation, not to consume alcoholic beverages and not to perform intense physical exercise 24 hours before data collection and also to eat a light diet on the day. During both pre and post-exercise data collection they were placed in the supine position on a stretcher where they remained at rest for five minutes. To calibrate the device, data on age, sex, body mass and 
height were provided according to the manufacturer's instructions. Two inflatable cuffs were attached to the middle finger of the left hand and the left arm of the individual. For the taking of measurements, the device was calibrated until the excellent signal was obtained. Subsequently, during the pre-exercise stage, the hemodynamic variables were monitored continuously for 10 minutes, with the average values from this period recorded for analysis purposes. During the post-exercise stage, after calibration, monitoring was performed continuously for 60 minutes, with the average of the variables recorded every 15 minutes for analysis purposes.

The exercise sessions took the form of collective aerobics classes, with an average duration of 50 minutes, consisting of warm-up, the main exercise part and relaxation, with the aim of developing aerobic capacity and muscle strength. The warm-up lasted 10 minutes and consisted of aerobic activities (such as walking around the room), together with warm-up of the joints of the upper and lower limbs. The main part of the exercise lasted approximately 30 minutes, and was composed of static and dynamic resistance exercises for the lower and upper limbs. At the end of the session, about 10 minutes were used for relaxation, through the performance of passive or active static stretching exercises.

The intensity of these classes was measured using an accelerometer (Actigraph, model GT3X +) attached to the participants' right hip. The cut-off point adapted by Buman et al. ${ }^{12}$ was adopted to categorize the intensity of effort achieved in four levels: sedentary, low-light physical activity, high-light physical activity and moderate to vigorous physical activity.
First, a descriptive analysis was carried out to characterize the sample, with the presentation of quantitative data in means and standard deviations and categorical data in absolute and relative frequencies. The Shapiro-Wilk test was performed for the analysis of data normality. To compare the values of hemodynamic variables from the preto the post-exercise phase, a one-way analysis of variance (ANOVA) was performed for repeated measures, after confirming normality. The Bonferroni post-hoc test was used to identify the differences in the variables for which the ANOVA values found were superior to the established criterion of statistical significance $(p<0.05)$. For variables without a normal distribution, the Kruskal-Wallis non-parametric test was used. To test the correlation between the deltas $(\Delta)$ of the SBP and DBP variables with the intensity of the classes and with the $\Delta$ of the CO and the PVR variables, the Pearson test was used for data with normal distribution and the Spearman test for data that did not show normality. The level of statistical significance established was $p<0.05$. All analyzes were performed using the statistical package $\mathrm{R}$, version 3.5.3.

\section{RESULTS}

Table 1 presents the descriptive data of the sample and the pre-exercise values of the hemodynamic variables. Analyzing the mean BMI, the older women, in general, were classified as overweight. Half of the participants (seven) used two or more medications for the treatment of SAH. The sample was composed of six married women (43\%), followed by four widows $(28.6 \%)$ and four divorced women $(28.6 \%)$. 
Table 1. General characteristics of the sample and hemodynamic values prior to exercise (n=14). Florianópolis (Santa Catarina), Brazil, 2018.

\begin{tabular}{ll}
\hline Variables & Mean \pm standard deviation \\
\hline Age (years) & $72.0 \pm 6.7$ \\
\hline Height $(\mathrm{cm})$ & $156.1 \pm 6.7$ \\
\hline Body mass $(\mathrm{kg})$ & $67.7 \pm 9.6$ \\
\hline Body mass index $\left(\mathrm{kg} / \mathrm{m}^{2}\right)$ & $27.8 \pm 3.3$ \\
\hline Time since diagnosis of hypertension (years) & $18.0 \pm 9.4$ \\
Pre-exercise SBP $(\mathrm{mmHg})$ & $142.4 \pm 14.5$ \\
\hline Pre-exercise DBP $(\mathrm{mmHg})$ & $69.5 \pm 9.6$ \\
\hline Pre-exercise HR $(\mathrm{bpm})$ & $64.2 \pm 10.4$ \\
\hline Pre-exercise SV $(\mathrm{ml})$ & $94.4 \pm 32.8$ \\
\hline Pre-exercise CO $(\mathrm{l} / \mathrm{min})$ & $6.0 \pm 2.2$ \\
\hline Pre-exercise PVR $\left(\right.$ dyn.s $\left./ \mathrm{cm}^{5}\right)$ & $1502.7 \pm 654.8$ \\
\hline
\end{tabular}

$\mathrm{SBP}=$ systolic blood pressure; $\mathrm{DBP}=$ diastolic blood pressure; $\mathrm{HR}=$ heart rate; $\mathrm{SV}=$ stroke volume; $\mathrm{CO}=$ cardiac output; $\mathrm{PVR}=$ peripheral vascular resistance.

Regarding the intensities of effort of the classes, it was observed that they were, predominantly, composed of low intensity activities (60\%), which corresponded to 23.9 minutes of the classes. However, considerable class time $(20 \%)$ was spent on sedentary behavior (8.1 minutes). Less time was devoted to activities of high-light $(12 \%)$ and moderate to vigorous $(8 \%)$ intensity, which corresponded to 4.8 and 3.2 minutes, respectively.

Figure 2 shows the behavior of the SBP, DBP, $\mathrm{HR}, \mathrm{SV}, \mathrm{CO}$ and PVR variables during the postexercise follow-up period, compared to the preexercise values.

When comparing the pre and post-exercise values of all the measurement times, there was no statistically significant difference for any of the variables analyzed ( $p>0.05)$. For SBP, although the mean after 15 minutes showed a reduction in relation to the pre-exercise phase (137.2 \pm 14.8 vs $142.4 \pm 14.5)$, which would indicate post-exercise hypotension, the reduction was not significant $(p>0.05)$. The increases visually identified for the different variables were also not statistically significant.

Table 2 shows the correlations between the SBP and DBP deltas $(\Delta)$, calculated using the average of the four post-exercise measurements $\left(15^{\prime}, 30^{\prime}, 45^{\prime}\right.$ and $\left.60^{\prime}\right)$ minus the pre-exercise value, with the average time spent at the different intensities achieved in the sessions: sedentary, low-light, high-light and moderate to vigorous.

A moderate positive correlation was observed between the $\triangle$ SBP and the time spent in sedentary behavior ( $r=0.541 ; \mathrm{p}=0.045)$, suggesting that the greater the time spent in sedentary behavior during sessions, the greater the increase in SBP. The other correlations were weak and had no statistical significance $(r<0.5 ; \mathrm{p}>0.05)$.

Table 3 shows the correlation between the SBP and DBP deltas $(\Delta)$ and the CO and PVR deltas $(\Delta)$, for the participants with PEH only. 


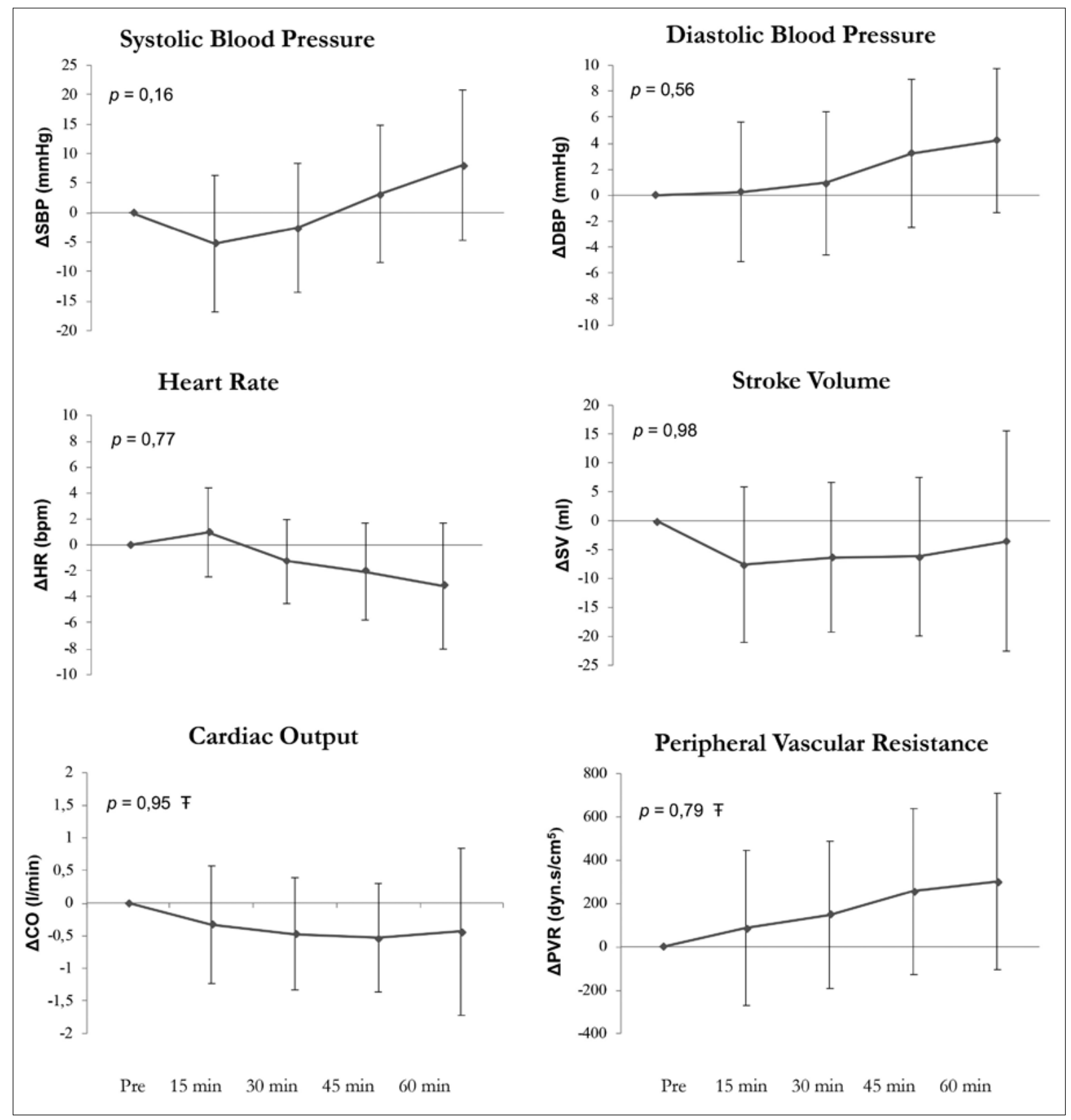

Figure 2. Behavior of the hemodynamic variables at moments 15, 30, 45 and 60 minutes post-exercise in relation to the pre-exercise phase. The values are represented by delta $(\Delta)$. The value adopted for statistical significance was

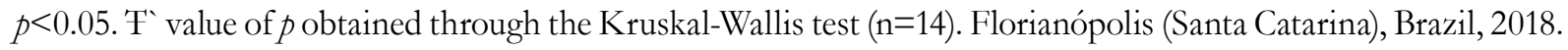

Table 2. Correlation between SBP and DBP deltas with the average time spent in class at each intensity of effort (n=14). Florianópolis (Santa Catarina), Brazil, 2018.

\begin{tabular}{lllllllll}
\hline & SED & p-value & $\begin{array}{l}\text { Low-Light } \\
\text { PA }\end{array}$ & $p$-value & $\begin{array}{l}\text { High-Light } \\
\text { PA }\end{array}$ & $p$-value & MVPA & $p$-value \\
\hline$\Delta$ SBP & 0.541 & $0.045^{*}$ & 0.168 & 0.565 & -0.189 & 0.516 & $0.114^{*}$ & 0.696 \\
\hline$\Delta$ DBP & 0.257 & 0.374 & 0.115 & 0.694 & -0.347 & 0.223 & $-0.064^{*}$ & 0.827 \\
\hline
\end{tabular}

$\triangle \mathrm{SBP}=$ changes observed in $\mathrm{SBP}$ between the pre-exercise phase and the mean of the post-exercise measurement times; $\Delta \mathrm{DBP}=$ changes observed in DBP between the pre-exercise phases and the mean of the post-exercise measurement times; $*$ Spearman's correlation; $\mathrm{p}$-value $<0.05$. 
Table 3. Correlation of SBP, DBP, CO and PVR deltas in participants with PEH (n=7). Florianópolis (Santa Catarina), Brazil, 2018.

\begin{tabular}{lllll}
\hline & $\Delta$ CO & $p$-value & $\Delta$ PVR & $p$-value \\
\hline$\Delta$ SBP & -0.336 & 0.460 & 0.573 & 0.177 \\
$\Delta$ DBP & 0.346 & 0.446 & -0.273 & 0.553 \\
\hline$\Delta$ SBP &
\end{tabular}

$\triangle \mathrm{SBP}, \triangle \mathrm{DBP}, \Delta \mathrm{CO}$ and $\triangle \mathrm{PVR}=$ changes observed in hemodynamic variables between the pre-exercise phase and the mean of the post-exercise measurement times.

Among the seven older women with a reduction in SBP from the pre- to the post-exercise (the mean of all the post-exercise measurement times) phases, there was no significant correlation with the changes identified in PVR or $\mathrm{CO}(p>0.05)$. The same scenario was observed for the seven older women who exhibited a reduction in DBP from the pre- to the post-exercise phase (mean of all the post-exercise measurement times) $(p>0.05)$.

\section{DISCUSSION}

The main findings of the present study indicate that $\mathrm{PEH}$ was not observed in response to a combined exercise session, in a collective class format, in hypertensive older women. According to the results found, at the end of the 60-minute post-exercise follow-up period, there were nonstatistically significant increases of about $8 \mathrm{mmHg}$ for SBP and $4 \mathrm{mmHg}$ for DBP. In addition, the increase in SBP values was associated with time spent on activities classified as sedentary during the session ( 8.1 minutes). Thus, the greater the time spent in sedentary activities during class, the greater the increase in post-exercise SBP, which is similar to what has been observed in other studies that evaluated the association between sedentary periods and biomarkers in older individuals ${ }^{13}$.

The results found in the present study differ from other previous studies that observed PEH in older women after an exercise session ${ }^{6,14}$. In the study by Santana et al., hypertensive older women undergoing an exercise session of moderate and vigorous intensity exhibited $\mathrm{PEH}$ in sessions of both intensities in comparison with the control session ${ }^{14}$. In the study by Moreira et $\mathrm{al}^{6}{ }^{6}$, a resistance exercise session, performed with three sets of 12 repetitions at $60 \%$ of $1 \mathrm{RM}$ in each exercise, brought about
PEH in medicated hypertensive older women. In both studies, the sessions were not performed with combined exercises and the intensities achieved were moderate to vigorous, which could explain the differences in results in relation to the present study.

Furthermore, the results observed in the present study are contrary to most previous studies that demonstrated a hypotensive effect in response to a combined exercise session ${ }^{15-18}$. Among these, the study by Ferrari et al. ${ }^{16}$ demonstrated that combined exercise caused acute PEH after one hour, similar to aerobic exercise performed on its own. Similarly, in the study by Anunciação et al., carried out with controlled hypertensive older women, it was found that aerobic and combined exercise sessions promoted significant reductions in SBP and DBP at 30, 60, 120 and 180 minutes post-exercise ${ }^{18}$. The different results observed between such studies and the present study could be explained by the divergence between the exercise protocols used, since the present study was unable to strictly control the intensity of the strength exercises.

Furthermore, Teixeira et al. ${ }^{19}$ evaluated young normotensive individuals who performed aerobic exercise at greater volume and at high intensities ( $75 \%$ of maximum $\mathrm{VO}_{2}$ ) during the session, which seems to be the most effective protocol for $\mathrm{PEH}^{5}$. It is important to note that the studies cited evaluated subjects with different characteristics from the sample of the present study and that none measured intensity using an accelerometer, making comparative analysis difficult.

Additionally, a study by Menêses et al. ${ }^{20}$, with medicated hypertensive women, evaluated the behavior of hemodynamic parameters for 30 minutes after a resistance exercise session at $50 \%$ of $1 \mathrm{RM}$ intensity and aerobic exercises between 50 and $60 \%$ 
of reserve HR. The results did not demonstrate statistically significant changes in SBP and DBP after exercise, similar to the findings of the present study. On the other hand, in the control session conducted in that study, significant increases were identified for both SBP and DBP. As in the present study, $\mathrm{CO}$ and PVR also remained unchanged in the study by Menêses et al. ${ }^{20}$. However, in contrast with what was observed in the present study, reductions in $\mathrm{SV}$ and increases in HR were observed.

In the present study, the behavior of post-exercise $\mathrm{BP}$ was not associated with CO and PVR among the older women who exhibited PEH. Literature, in turn, suggests that either of these variables, if not both, would explain PEH, but this tends to vary from person to person. As stated by Queiroz et al. ${ }^{21} \mathrm{PEH}$ can be caused either by a reduction in PVR, or by a reduction in $\mathrm{CO}$, which did not occur in the present study and prevented the finding of an association between BP responses and one or another determinant when the sample was analyzed as a set. In this context, Brito et al. ${ }^{9}$ found that CO is usually the most influential factor in untrained male individuals, who are older (consistent with the findings of the present study) with a higher BMI, while PVR usually has a greater effect in the opposite cases. Specifically in older individuals, the increase in arterial stiffness and the decrease in endothelial function associated with aging could make it difficult to reduce PVR after exercise.

It is possible that the occurrence of PEH observed in the aforementioned studies was due to the higher intensity of effort in the exercise sessions, which is notable even when considering that different methods for determining intensity were used. In addition, in these studies it was possible to control intensity with greater rigor, due to the previously performed tests, which meant that all participants should have expended equal effort. This was not possible in the present study, since interfering with the characteristics of the class did not form part of the proposal. Instead the objective was precisely to identify the intensity of the classes taught in the project analyzed, and whether they were sufficient to promote $\mathrm{PEH}$, without prescribing or controlling the same.
From a practical point of view, the present study is relevant, since it evaluates, in the specific aspect of post-exercise BP behavior, a collective exercise class for older women, which can provide reflections for professionals who work in this area regarding how to guide such classes. Despite some individuals exhibiting PEH, it was found that, in the manner in which it was applied, the class did not provide optimal results in terms of BP reduction for the studied group, older hypertensive women, who, perhaps, are those who have the treatment of the condition as one of the primary motivations for adherence to the exercise program. In this sense, it may be useful to seek strategies to intensify the class, or to use a more rigorous method to control it. It is worth mentioning that, in addition to the specific benefit of PEH, it is likely that the class will have a positive effect on other components of physical fitness related to health, well-being and functional capacity. These requirements, however, were not assessed in the present study.

The present study has certain limitations which must be considered. For example, a control session was not carried out, and it was not possible to verify whether the exercise sessions prevented an increase in BP which, perhaps, would occur in the absence of exercise. In addition, between the end of the class and the beginning of the assessment, time was required to move and calibrate the equipment, which in general amounted to almost 20 minutes, and only following this were the 15, 30, 45 and 60 minutes post-exercise calculated. In other words, the time immediately after the exercise was not considered, unlike in cases in which the measurements are made by means of an automatic device, which compromises, to a certain degree, the moment-to-moment comparison of BP behavior with other studies that did not use the Finometer device. Furthermore, it should be noted that while accelerometry is currently considered a reference measure for physical activity, there are limitations regarding the evaluation of muscle strengthening activities $^{22}$. It should also be considered that the older women used medications of different classes and took them at different times, a factor which 
was not assessed in the present study. The first case implies that hypertensive patients have their condition sustained, and therefore treated, through different mechanisms ${ }^{1}$ and, therefore, may have responded to the exercises differently. In the second case, individuals who took medication just before the session may have suffered interference from its more immediate effects.

Furthermore, there are still gaps in the scope of the acute and chronic effect of physical exercise on BP. It is suggested that future studies investigate whether there would be chronic adaptation in BP using this class model, even in the absence of PEH. In addition, it is suggested that it is investigated whether, during the 24 hour period following exercise, a hypotensive effect is manifested, in comparison to days without exercise.

\section{CONCLUSION}

Based on the results, it can be concluded that a single session of combined exercises performed in group classes was not able to promote $\mathrm{PEH}$ in hypertensive older women. The intensity of effort achieved in classes was, predominantly, low-light and considerable time was spent in sedentary behavior. In addition, the time spent on typically sedentary activities during sessions showed a positive correlation with changes in SBP. Therefore, in order to promote the beneficial effects of exercise on blood pressure levels in hypertensive older women, it is suggested that combined exercise programs, applied in the form of collective aerobics classes, be made up of higher intensity activities.

Edited by: Ana Carolina Lima Cavaletti

\section{REFERENCES}

1. Sociedade Brasileira de Cardiologia, Sociedade Brasileira de Hipertensão, Sociedade Brasileira de Nefrologia. 7a Diretriz Brasileira de Hipertensão Arterial. Arq Bras Cardiol. 2016;107(3 Supl 3):1-103.

2. Whelton PK, Carey RM, Aronow WS, Casey DE, Collins KJ, Dennison Himmelfarb C, et al. 2017 Guideline for the prevention, detection, evaluation, and management of high blood pressure in adults. J Am Coll Cardiol. 2018;71(19):127-248.

3. MacDonald HV, Farinatti PV, Lamberti L, Pescatello LS. Effects of concurrent exercise on hypertension: Current Consensus and Emerging Research. In: Pescatello LS, organizador. Effects of Exercise on Hypertension. Cham: Springer International Publishing; 2015. p. 47-86.

4. Pescatello LS, Franklin BA, Fagard R, Farquhar WB, Kelley GA, Ray CA, et al. American College of Sports Medicine position stand. Exercise and hypertension. Med Sci Sports Exerc. 2004;36(3):533-53.

5. Anunciação PG, Polito MD. Hipotensão pósexercício em indivíduos hipertensos: uma revisão. Arq Bras Cardiol. 2011;96(5):425-6.

6. Moreira SR, Cucato GG, Terra DF, Ritti-Dias RM. Acute blood pressure changes are related to chronic effects of resistance exercise in medicated hypertensives elderly women. Clin Physiol Funct Imaging. 2014;36(3):242-8.
7. MacDonald HV, Pescatello LS. Exercise prescription for hypertension: new advances for optimizing blood pressure benefits. In: Ross R, Zibadi S. Lifestyle in heart health and disease. [no place]: Elsevier; 2018. p.115-36.

8. Pescatello LS, MacDonald HV, Lamberti L, Johnson BT. Exercise for hypertension: a prescription update integrating existing recommendations with emerging research. Curr Hypertens Rep. 2015;17(11):1-10.

9. Brito LC, Queiroz ACC, Forjaz CLM. Influence of population and exercise protocol characteristics on hemodynamic determinants of post-aerobic exercise hypotension. Braz J Med Biol Res. 2014;47(8):626-36.

10. Amorim T, Knuth A, Cruz D, Malta D, Reis R, Hallal P. Descrição dos programas municipais de promoção da atividade física financiados pelo Ministério da Saúde. Rev Bras Ativ Fís Saúde. 2013;18(1):63-74.

11. Borges LJ, Meurer ST, Borges RA, Gerage AM, Benedetti TRB. Qual a intensidade das aulas de um programa de exercício físico para idosos? Rev Bras Cineantropom Desempenho Hum. 2015;17(5):1-12.

12. Buman MP, Hekler EB, Haskell WL, Pruitt L, Conway TL, Cain KL, et al. Objective light-intensity physical activity associations with rated health in older adults. Am J Epidemiol. 2010;172(10):1155-65.

13. Wirth K, Klenk J, Brefka S, Dallmeier D, Faehling K, Roqué I, et al. Biomarkers associated with sedentary behaviour in older adults: A systematic review. Ageing Res Rev. 2017;35:87-111. 
14. Santana HAP, Moreira SR, Asano RY, Sales MM, Córdova C, Campbell CSG, et al. Exercise intensity modulates nitric oxide and blood pressure responses in hypertensive older women. Aging Clin Exp Res. 2013;25(1):43-8.

15. Lovato NS, Anunciação PG, Polito MD. Pressão arterial e variabilidade de frequência cardíaca após o exercício aeróbio e com pesos realizados na mesma sessão. Rev Bras Med Esporte. 2012;18(1):22-5.

16. Ferrari R, Umpierre D, Vogel G, Vieira PJC, Santos LP, de Mello RB, et al. Effects of concurrent and aerobic exercises on postexercise hypotension in elderly hypertensive men. Exp Gerontol. 2017;98:1-7.

17. Luttrell MJ, Halliwill JR. Recovery from exercise: vulnerable state, window of opportunity, or crystal ball? Front Physiol. 2015;1-16.

18. Anunciação PG, Farinatti PTV, Goessler KF, Casonatto J, Polito MD. Blood pressure and autonomic responses following isolated and combined aerobic and resistance exercise in hypertensive older women. Clin Exp Hypertens. 2016;38(8):710-4.
19. Teixeira L, Ritti-Dias RM, Tinucci T, Mion Júnior D, Forjaz CLM. Post-concurrent exercise hemodynamics and cardiac autonomic modulation. Eur J Appl Physiol. 2011;111(9):2069-78.

20. Menêses AL, Forjaz CLM, de Lima PFM, Batista RMF, Monteiro MF, Ritti-Dias RM. Influence of endurance and resistance exercise order on the post exercise hemodynamic responses in hypertensive women. J Strength Cond Res. 2015;29(3):612-8.

21. Queiroz ACC, Sousa JCS, Cavalli AP, Silva ND, Costa LAR, Tobaldini E, et al. Postresistance exercise hemodynamic and autonomic responses: Comparison between normotensive and hypertensive men. Scand J Med Sci Sports. 2014;25(4):486-94.

22. Chen KY, Janz KF, Zhu W, Brychta RJ. Redefining the roles of sensors in objective physical activity monitoring. Med Sci Sports Exerc. 2012;44:13-23. 